\title{
MONOGRAFIE/MONOGRAPH
}

Valérie Tothová, Věra Hellerová (eds) (2021). Využití měřicích nástrojů v ošetřovatelství [Use of measuring instruments in nursing]. Praha. NLN, s. r. o. 225 s. ISBN 978-80-7422-817-9. DOI: 10.32725/zsf.2021.74228179

\section{Využití měřcích nástrojů u žen v období klimakteria}

kap. 8: DOI: 10.32725/zsf.2021.74228179.06

\section{Romana Belešová}

University of South Bohemia in České Budějovice, Faculty of Health and Social Sciences, Institute of Nursing, Midwifery and Emergency Care, České Budějovice, Czech Republic

\section{Souhrn}

Prezentovaný výzkum při hodnocení kvality vlastního života u velké většiny žen potvrdil kvalitu života jako dobrou, stejně tak i majoritní počet žen uvedl spokojenost s vlastním zdravím. Dále je z odhalených výsledků výzkumu zřejmé, že při vyhodnocení zdraví žen pocitují ženy nejméně úzkost/obavy, vedle toho se u nich nejčastěji vyskytují vazomotorické př́iznaky.

$\checkmark$ této souvislosti je nutno zmínit fakt, že i když na období klimakteria větší část naší společnosti nahliží jako na zcela přirozenou součást ženského života, je podstatné, abychom pomáhali ženám v tomto obtížném životním období vyrovnat se s ním a prožívat jej ve zdraví a kvalitně.

Na závěr je významné $v$ kontextu $s$ dosaženými výsledky, dokládajícími důležitost v provádění změn v životním stylu, vyzdvihnout význam edukace, se zaměřením na zdravý životní styl a na jeho vliv na kvalitu života a kvalitu zdraví žen. Na základě zmiňovaného argumentu vnímáme jako podstatné informovat ženy ještě před nástupem menopauzy o problematice symptomů, změn, které se mohou u žen vyskytovat $v$ souvislosti s následným estrogenním deficitem. Stěžejní roli by $v$ této oblasti měly zastávat porodní asistentky $v$ rámci svých kompetencí, $\mathrm{s}$ cílem poskytovat kvalitní a efektivní péči ženám.

Klíčová slova: klimakterium, kvalita života, měricí nástroje, porodní asistentka, žena

\section{Podkapitoly:}

8.1 Teoretické vymezení klimakteria

8.2 Symptomy, změny a potřeby $v$ klimakteriu

8.2.1 Znalosti žen o symptomech

8.2.2 Subjektivní vnímání symptomů

8.2.3 Zdroje informací a znalosti problematiky klimakteria

8.2.4 Potřeby a jejich změny $v$ klimakteriu

8.3 Diagnostika a terapie $v$ období klimakteria

8.4 Zdraví a klimakterium

8.4.1 Měřicí nástroje zaměřené na zdraví žen v klimakteriu

8.5 Kvalita života žen v klimakteriu

8.5.1 Měřicí nástroje zaměřené na kvalitu života žen

8.6 Klimakterium z pohledu komparace vzájemných souvislostí

8.7 Životní styl a klimakterium 


\section{Literatura}

1. Al-Musa, H. M., et al. (2017). The prevalence of symptoms experienced during menopause, influence of socio-demographic variables on symptoms and quality of life among women at Abha Saudi Arabia. Biomed Res 28(6): 2587-2595.

2. AlQuiaz A. M., et al. (2013) Assessment of symptoms of menopause and their severity among Saudi women in Riyadh. Ann Saudi Med 33(1): 63-67. DOI: 10.5144/0256-4947.2013.63.

3. Bašková, M. (2008). Sexuálne potřeby. In: Tomagová, M., Bóriková, I., a kol. Potreby v ošetrovatel'stve. Martin: Osveta, $196 \mathrm{~s}$.

4. Belešová, R., Tóthová, V. (2019). Use of evaluation tools to evaluate symptoms and changes in climacteric women in the Czech Republic and abroad. Cent Eur J Nurs Midw 10(4): 1143-1154. DOI: 10.15452/CEJNM.2019.10.0026

5. Belešová, R., Tóthová, V. (2020). Ženy v klimakteriu a jejich životní styl. Zdravotnícke štúdie. XII(2): 2833.

6. Belešová, R., Tóthová, V. (2021a). Kvalita života ženy v období prechodu od reprodukční do postreprodukční fáze života. Zdravotnícke listy [v recenzním řízení].

7. Belešová, R., Tóthová, V. (2021b). Findings from the Study on Women's Quality of Life and Quality of Health; Comparison of Correlations in Climacteric Women from the Czech Republic. Healthcare [v recenzním řízení].

8. Bělehradová, I., Hodická, Z. (2012). Využití fytoestrogenů v gynekologii. Prakt Gyn 16(1): 13-15

9. Bien, A., et al. (2015). The Influence of Climacteric Symptoms on Women's Lives and Activities. Int J Environ Res Public Health 12(4): 3835-3846. DOI: 10.3390/ijerph120403835.

10. Blümel, J. E., et al. (2015). Obesity and its relation to depressive symptoms and sedentary lifestyle in middle-aged women. Maturitas 80(1): 100-105. DOI: 10.1016/j.maturitas.2014.10.007.

11. Bóriková, I. (2008). Pohybová aktivita. In: Tomagová, M., Bóriková, I., a kol. Potreby v ošetrovatel'stve. Martin: Osveta, $196 \mathrm{s.}$

12. Caan, B., et al. (2015). Effects of Estrogen or Venlafaxine on Menopause Related Quality od Life in Healthy Randomized Trial. Menopause 22(6) 607-615. DOI: 10.1097/GME.0000000000000364.

13. Cano, A. (2017). Menopause: The Concepts and the Biological Background, s. 9-21. DOI: 10.1007/978-3319-59318-0_2.

14. Capistrano, E. J. M., et al. (2015). Factors associated with the severity of menopausal symptoms in postmenopausal Brazilien women. Reproduçăo \& Climatério. 30(2): 70-76. DOI: 10.1016/j.recli.2015.09.002.

15. Csémy, L., a kol. (2019). Užívání alkoholu a tabáku v České republice 2018. Státní zdravotní ústav, s. 140. [online] [citováno 2019-08-06]. Dostupné z: http://www.szu.cz/uploads/documents/szu/aktual/uzivani_tabaku_alkoholu_cr_2018.pdf

16. Csete, M. (2016). 1000 tipů pro zdraví. Nové Zámky: Ex, $144 \mathrm{~s}$.

17. Čeledová, L., Čevela, R. (2010). Výchova ke zdraví - vybrané kapitoly. Praha: Grada.

18. Čepický, P. (2011). Gynekologická endokrinologie. In: Roztočil, A., a kol.. Moderní gynekologie. Praha: Grada.

19. da Silva, A. R., d'Andretta Tanaka, A. C. (2013). Factors associated with menopausal symptom severity inmiddle-aged Brazilian women from the Brazilian Western Amazon. Maturitas 76(1): 64-69. DOI: 10.1016/j.maturitas.2013.05.015.

20. de Zambotti, M., et al. (2014). Magnitude of the impact of hot flashes on sleep in perimenopausal vomen. Fertil Steril 102(6): 1708-1715. DOI: 10.1016/j.fertnstert.2014.08.016.

21. Dostál, J., Pilka, R. (2017). Endokrinologie a menstruační cyklus. In: Pilka, R., a kol. Gynekologie. Praha: Maxdorf, $332 \mathrm{~s}$.

22. Dostál, J., Turková, M. (2017). Perimenopauza a postmenopauza. In: Pilka, R., a kol. Gynekologie. Praha: Maxdorf, $332 \mathrm{~s}$. 
23. Dragomirecká, E., Bartoňová, J. (2006). WHOQOL-BREF, WHOQOL-100 - príručka pro uživatele české verze dotazníků kvality života Světové zdravotnické organizace. Praha: Psychiatrické centrum, $88 \mathrm{~s}$.

24. Drbal, C., Bencko, V. (2005). Prostředí, zdraví, jeho determinanty a kvalita života. In: Payne, J., a kol. Kvalita života a zdraví. Praha: Triton, $630 \mathrm{~s}$.

25. Fait, T. (2008). Možnosti objektivizace akutního klimakterického syndromu. Prakt Gyn 12(4): $230-235$.

26. Fait, T. (2013). Klimakterická medicína. Praha: Maxdorf, $228 \mathrm{~s}$.

27. Fait, T. (2015). Nehormonální terapie klimakterického syndromu. Prakt Gyn. 19(2): 123-126.

28. Fait, T. (2016). Od fytoestrogenů k fytoSERMům. Klimakterická Medicína 21(2): 19-20.

29. Fait, T. (2017a). Klasifikace STRAW + 10. Klimakterická Medicína 22(2): 8-10.

30. Fait, T. (2017b). The 2017 HT Position Statement of NAMS. Klimakterická Medicína 22(2): 24-27.

31. Faraji, K., et al. (2018). Could a Midwife Leading Health Behaviour Counseling Improve Self-Care of Women During Perimenopause? A Quasi- Experimental Study. J Midlife Health 9(4): 195-199. DOI: 10.4103/jmh.JMH_18_17.

32. Farkašová, D., a kol. (2006). Ošetřovatelství - teorie. Martin: Osveta, $211 \mathrm{s.}$

33. Genazzani, A. R. (2017). První volba pro řešení menopauzálních symptomů DT56a, nehormonální přírodní terapie. Klimakterická Medicína 22(4): 26.

34. Ghazanfarpour, M., et al. (2013). Association between anthropometric indices and quality of life in menopausal women. Gynecol Endocrinol 29(10): 917-920. DOI: 10.3109/09513590.2013.819078.

35. Giannouli, P., et al. (2012). Determinants of quality of life in Greek middle-age women: A population survey. Maturitas 71(2): 154-161. DOI: 10.1016/j.maturitas.2011.11.013.

36. Gonçalves, J. T. T., et al. (2016). Sobrepeso e obesidade e fatores associados ao climatério. Ciência \& Saúde Coletiva. 21(4): 1145-1156. DOI: 10.1590/1413-81232015214.16552015.

37. Greene, J. (1998). Constructing a standard climacteric scale. Maturitas 29(1): 25-31. DOI: 10.1016/s0378-5122(98)00025-5.

38. Grochans, E., et al. (2018). Analysis of Sociodemographic, Psychological, and Genetic Factors Contributing to Depressive symptoms in Pre-, Peri- and Postmenopausal Women. Int J Environ Res Public Health 15(4): 712. DOI: 10.3390/ijerph15040712.

39. Gurková, E. (2011). Hodnocení kvality života - pro klinickou praxi a ošetřovatelský výzkum. Praha: Grada, 224 s.

40. Harlow, S. D., et al. (2012). Executive summary of the Stages of Reproductive Aging Workshop + 10: adressing the unfinished agenda of stagimg reproductive aging. J Clin Endocrinol Metab 97(4): 11591168. DOI: 10.1210/jc.2011-3362.

41. Hauke, M. (2011). Pečovatelská služba a individuální plánování. Praktický průvodce. Praha: Grada.

42. Heinemann, K., et al. (2004). The Menopause Rating Scale (MRS): a methodological review. Health Qual Life Outcomes 2: 45. DOI: 10.1186/1477-7525-2-45.

43. Heinemann, L. A. J., et al. (2003). International versions of the Menopause rating Scale (MRS). Health Qual Life Outcomes 1: 28. DOI: 10.1186/1477-7525-1-28.

44. Heřmanová, E. (2012). Koncepty, teorie a měření kvality života. Praha: SLON, 239 s.

45. Hirose, A., et al. (2018). Effect of soy lecithin on fatigue and menopausal symptoms in middle-aged women: a randomized, double-blind, placebo-controlled study. Nutr J 17(1): 1-8. DOI: 10.1186/s12937018-0314-5.

46. Holub, J. T. (2014). Jak se léčit homeopatií ve středním a vyšším věku. Brno: Albatros Media.

47. Hudáková, Z. (2018). Pohybová aktivita a životný štýl vo vyššom veku. Břeclav: Sovenio, 144 s.

48. Hudáková, A., Majerníková, Ĺ. (2013). Kvalita života seniorů v kontextu ošetřovatelství. Praha: Grada, $128 \mathrm{~s}$.

49. Hunter, M. S. (2000). The Women's Health Questionnaire (WHQ): The development, standardization and application of a measure of mid-aged women's emotional and physical health. Quality of Life Research 9: 733-738. DOI: 10.1023/A:1008973822876.

50. Hunter, M. S. (2003). The Women's Health Questionnaire (WHQ): Frequently Asked Questions (FAQ). Health and Quality of Life Outcomes 1(41): 1-5. DOI: 10.1186/1477-7525-1-41. 
51. Hunter, M. S., Chilcot, J. (2013). Testing a cognitive model of menopausal hot flushes and night sweats. J Psychosom Res 74(4): 307-312. DOI: 10.1016/j.jpsychores.2012.12.005.

52. Jeníček, J. (2016). Sérélys - nový přístup k řešení akutních příznaků menopauzy. Klimakterická Medicína 21(4): 15-17.

53. Jeníček, J. (2018). Kyselina hyaluronová v léčbě suchosti poševní sliznice a dalších indikacích. Klimakterická Medicína 23(2): 23-25.

54. Jessel, Ch. (2006). Úspěšně proti osteoporóze - preventivní a bolest zmírňující cvičení. BETA Dobrovský, $95 \mathrm{s.}$

55. Juklová, K., et al. (2015). Vybrané kapitoly z pedagogiky a psychologie nejen pro speciální pedagogy. Hradec Králové: Gaudeamus, 160 s.

56. Kastnerová, M. (2012). Poradce zdravého životního stylu. České Budějovice: Nová Forma, 378 s.

57. Kim, J.-E., et al. (2017). Effect of Guizhifulingwan (Keishibukuryogan) on climacteric syndrome: study protocol for a randomized controlled pilot trial. Trials 18(1): 135. DOI: 10.1186/s13063-017-1877-8.

58. Kim, K. H., et al. (2010). Effects of acupuncture on hot flashes in perimenopausal and postmenopausal women-a multicenter randomized clinical trial. Menopause 17(2): 269-280. DOI: 10.1097/gme.0b013e3181bfac3b.

59. Kim, M., et al. (2018). Danggwijagyaksan for climacteric syndrome in peri- and postmenopausal women with a blood-deficiency dominant pattern: study protocol for a randomized, double-blind, placebocontrolled pilot trial. Trials 19(1): 41. DOI: 10.1186/s13063-018-2443-8.

60. Krejčík, V. (2013). Powerjóga nová cesta. Praha: Grada, 208 s.

61. Křepelka, J. (2017). Zdraví žen středního věku a hormonální terapie - doporučení IMS 2016 (International Menopause Society). Klimakterická Medicína 22(2): 8-12.

62. Kuberová, H. (2010). Didaktika ošetřovatelství. Praha: Portál.

63. Kubíková, D. (2014). Menopauzální symptomy a hormonální substituční terapie. Prakt Lékáren 10(2): 68-73.

64. Liu, Z., et al. (2014). Efficacy of electroacupuncture for symptoms of menopausal transition: study protocol for a randomized controlled trial. Trials 15: 242. DOI: 10.1186/1745-6215-15-242.

65. Llaneza, P. (2017). Clinical Symptoms and Quality of Life: Hot Flashes and Mood. In: Cano, C. Menopause. A Comprehensive Approach. Cham: Springer.

66. Machová, J. (2015). Definice životního stylu. In: Machová, J., Kubátová D., a kol. Výchova ke zdraví. Praha: Grada, 312 s.

67. Marečková, J. (2006). Ošetřovatelské diagnózy v NANDA doménách. Praha: Grada.

68. Marek, J., Hána, V., et al. (2017). Endokrinologie. Praha: Portál, 692 s.

69. Messina, M. (2014). Soy foods, isoflavones, and the health of postmenopausal women. Am J Clin Nutr 100(Suppl. 1): 423S-430S. DOI: 10.3945/ajcn.113.071464.

70. Ministerstvo zdravotnictví České republiky (2014). Zdraví 2020 - Národní strategie ochrany a podpory zdraví a prevence nemoci. Praha: Mz ČR.

71. Ministerstvo zdravotnictví České republiky (2018). Kvalifikační standard Porodní asistentka. Praha: MZ ČR. [online] [cit. 2020-12-14]. Dostupné z: https://www.mzcr.cz/Odbornik/dokumenty/kvalifikacnistandard-porodni-asistentka_16346_947_3.html

72. Mirkin, S., et al. (2019). Relationship between vasomotor symptom improvements and quality of life and sleep outcomes in menopausal women treated with oral, combined $17 \beta$-estradiol/progesterone. Menopause 26(6): 637-642. DOI: 10.1097/GME.0000000000001294.

73. Mishra, G. D. (2017). Menopause, A stage in the Life of Women. In: Cano, C. Menopause. A Comprehensive Approach. Cham: Springer.

74. Moravcová, M., Holá, J. (2017). Utilizing the Menopause Rating Scale questionnaire in electronic form for evaluating the quality of life in postmenopausal women. Kontakt 19(1): 13-18. DOI: 10.1016/j.kontakt.2017.01.008. 
75. Moravcová, M., et al. (2014). Menopause rating scale - validation Czech version specific instrument for assessing health-related quality of life in postmenopausal women. Ošetřovatelství a porodní asistence 5(1): 36-45.

76. Morisson, L. A., et al. (2014). Voices From the Hilo Women's Health Study: Talking Story About Menopause. Health Care Women Int 35(5): 529-548. DOI: 10.1080/07399332.2013.829067.

77. NANDA InternationalC (2015). Ošetřovatelské diagnózy. Definice a klasifikace 2015-2017. Praha: Grada.

78. Pastor, Z. (2010). Tajemství ženské sexuality. Kralice na Hané: Computer Media, $192 \mathrm{s.}$

79. Payne, J., a kol. (2005). Kvalita života a zdraví. Praha: Triton, $630 \mathrm{~s}$.

80. Pilka, R., Dvořák, V. (2017). Gynekologická anamnéza, vyšetření a diagnostické metody. In: Pilka, R., a kol. Gynekologie. Praha: Maxdorf.

81. Plevová, I., a kol. (2018). Ošetřovatelství I. 2. přepracované a doplněné vyd. Praha: Grada, 200 s.

82. Poněšický, J. (2006). Člověk a jeho postavení ve světě. Praha: Triton, 272 s.

83. Portman, D. J., Gass, M. L. S. (2014). Genitourinary syndrome of menopause: new terminology for vulvovaginal atrophy from the International Society for the Study of Women's Sexual Health and the North American Menopause Society. Menopause 21(10): 1063-1068. DOI: 10.1097/GME.0000000000000329.

84. Roztočil, A. (2011). Gynekologická propedeutika. In: Roztočil, A., a kol. Moderní gynekologie. Praha: Grada.

85. Roztočil, A., a kol. (2011). Moderní gynekologie. Praha: Grada.

86. Řehulka, E. (2011). School and Health 21. Education nad Healthcare. Brno: Masarykova univerzita.

87. Seeta Devi, A., et al. (2015). Assessment of Menopausal Symptoms Using Modified Menpause Rating Scale (MRS) Among Middle Age Women Urban and Rural Area of Pune Discrit J Adv Sci Res 6(3): 47-50.

88. Sherwood, G., Barnsteiner, J. (2012). Quality and Safety in Nursing: A Competency Approach to Improving Outcomes. Wiley-Blackwell.

89. Shifren, J. L., Gass, M. L. S. (2014). The North American Menopause Society recommendations for clinical care of midlife women. Menopause 21(10): 1038-1062. DOI: 10.1097/GME.0000000000000319.

90. Schneider, H. P., et al. (2000). The Menopause Rating Scale (MRS): Reliability of scores of menopausal complaints. Climacteric 3(1): 59-64. DOI: 10.3109/13697130009167600.

91. Simočková, V. (2011). Gynekologicko-pôrodnické ošetrovatel'stvo. Učebnica pre fakulty ošetrovatel'stva. Martin: Osveta, $216 \mathrm{s.}$

92. Slíva, J. (2016). Střevní mikrobiom ve vztahu k léčbě klimakterického syndromu. Klimakterická Medicína 21(4): 8.

93. Světová zdravotnická organizace (2001). Zdraví 21 - zdraví do 21. století. Praha: Světová zdravotnická organizace.

94. Šamánková, M., a kol. (2011). Lidské potřeby ve zdraví a nemoci - aplikované v ošetřovatelském procesu. Praha: Grada.

95. Taavoni, S., et al. (2014). Quality of Sleep and Its Related Factors in Postmenopausal Women in WestTehran. Womens Health Bull 1(3): 1-5. DOI: 10.17795/whb-23651.

96. Thorová, K. (2015). Vývojová psychologie. Proměny lidské psychiky od početí po smrt. Praha: Portál, 576 s.

97. Tomagová, M. (2008). Spánok a odpočinok. In: Tomagová, M., et al. Potreby v ošetrovatel'stve. Martin: Osveta.

98. Trachtová, E., a kol. (2018). Potřeby nemocného v ošetřovatelském procesu. 4. rozšířené vyd. Brno: NCO NZO, $261 \mathrm{~s}$.

99. Tranche, S., et al. (2016). Impact of a soy drink on climacteric symptoms: an open-label, crossover, randomized clinical trial. Gynecol Endocrinol 32(6): 477-482. DOI: 10.3109/09513590.2015.1132305.

100. Valjent, Z. (2013). Výchova k aktivnímu životnímu stylu (nejen zdravotnických záchranářů). Praha: Česká technika - nakladatelství ČVUT. 
101. Vora, R., Dangi, A. (2014). Effect of yoga on menopausal symptoms in the early menopausal period: A randomized controlled trial. Indian J Physiother Occup Ther 8(3): 49-53. DOI: 10.5958/09735674.2014.00355.4.

102. Vural, P. I., Yangin, H. B. (2017). Assessing Menopausal Symptoms among Turkish and German Women with the Menopause Rating Scale: A Cross-Cultural Study. Int J Car Sci 10(2): 979-986.

103. Vyhláška č. 55/2011 Sb., o činnostech zdravotnických pracovníků a jiných odborných pracovníků. In: Sbírka zákonů České republiky, částka 20/2011.

104. Wariso, B. A., et al. (2017). Depression during the menopause transition: impact on quality of life, social adjustment, and disability. Arch Womens Ment Health 20(2) 273-282. DOI: 10.1007/s00737-016-0701-x.

105. Webster, A. D., et al. (2018). Quality of life among postmenopausal women enrolled in the Minnesota Green Tea Trial. Maturitas 108: 1-6. DOI: 10.1016/j.maturitas.2017.10.013.

106. Worsley, R., et al. (2017). Moderate-severe vasomotor symptoms are associated with moderate-severe depresive symptoms. J Womens Health (Larchmt) 26(7): 712-718. DOI: 10.1089/jwh.2016.6142.

107. Yücel, C., Eroglu, K. (2013). Sexual Problems in Postmenopausal Women and Coping Methods. Sex Disabil 31(3): 217-228. DOI: 10.1007/s11195-013-9306-8.

108. Zanovitová, M. (2008). Výživa. In: Tomagová, M., et al. Potreby v ošetrovatel'stve. Martin: Osveta

109. Żołnierczuk-Kieliszek, D., et al. (2012). Quality of life in peri- and post-menopausal Polish women living in Lublin Province - Differences between urban and rural dwellers. Ann Agric Environ Med 19(1): 129133. 